\title{
Social Support in the Transition to Parenthood Among Lesbian, Gay, and Bisexual Persons: A Systematic Review
}

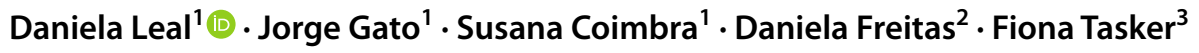

Accepted: 5 November 2020 / Published online: 6 January 2021

(c) Springer Science+Business Media, LLC, part of Springer Nature 2021

\begin{abstract}
Parenting is a challenging life-cycle transition, particularly for lesbian, gay, and bisexual (LGB) persons who have to deal with prejudice and discrimination. Considering this position of social disadvantage and the potential protective role of social support, our aim in this work was to systematize existing knowledge about the role of social support (i.e., social support, family support, community support, LGBT support, support, and engagement) in the transition to parenthood among LGB persons. Through a systematic review process conducted in May 2019 using PRISMA guidelines, the present study identified 22 manuscripts which accomplished all inclusion criteria. Our results suggested closer relationships to the family of origin and a detachment from the LGBT community in this stage of life cycle. Furthermore, the social support received in the transition to parenthood seems to influence not only the psychological well-being of these parents and prospective parents but also the quality of their relationships with different support networks. Thus, we understand that inclusive clinical and human professional interventions aimed at improving the available social support networks of LGB persons and, consequently, enhance their psychosocial well-being and family relations during this life transition.
\end{abstract}

Keywords Parenting $\cdot$ LGB $\cdot$ Systematic review $\cdot$ Transition to parenthood $\cdot$ Social support

\section{Introduction}

Parenthood among sexual minority persons has been enabled both by legal changes concerning marriage and adoption rights of lesbian, gay, and bisexual (LGB) persons, and increased access to assisted reproduction techniques (Goldberg, 2010a, b; Riskind \& Patterson, 2010). Despite these changes, parenthood remains a challenging life-cycle transition for LGB individuals (McGoldrick, Preto, \& Carter, 2015), given existing prejudice and discrimination against sexual minorities (Kaufman et al., 2017). In fact, studies have shown that even LGB persons who have not entered parenthood yet anticipate lower levels of social support (Baiocco \& Laghi, 2013) and higher levels of stigma

Daniela Leal

danielaleal@fpce.up.pt

Center for Psychology, University of Porto, Porto, Portugal

2 Institute of Psychiatric, Psychology, and Neuroscience, King's College London, London, England

3 Department of Psychological Sciences, Birkbeck University of London, London, England upon parenthood (Gato, Leal, \& Tasker, 2019; Leal, Gato, \& Coimbra, 2019a, b; Gato et al., 2020a, b, c) when compared with their heterosexual counterparts. Our main goal in this work was thus to explore the role of social support in the transition to parenthood among LGB individuals.

\section{The Transition to Parenthood Among LGB Persons}

The transition to parenthood includes the development of competency in parenting and the familiarity with the parenting behaviour (Bigner, 2006) and corresponds to the period which extends from the planning of parenthood (McGoldrick et al., 2015) until the first year of child's life (Nelson et al., 2014). This stage is a major developmental period with crucial consequences for couples, parents, the infant-parent relationship, and the infant's development (e.g., Nelson, Kushlev, \& Lyubomirsky, 2014). However, some specificities regarding this life transition among LGB persons might be considered. Given their minority status, LGB persons face additional challenges as parents and prospective parents. These 
challenges begin with the decisions concerning chosen pathways to parenthood that vary significantly (Farr \& Tornello, 2016). First, the assumption of a parental role may be seen with suspicion and LGB parents are often victims of social stigma (e.g., Goldberg, 2010a, b) or anticipate stigma upon parenthood (e.g., Leal, Gato, Coimbra, 2019a, b; Gato, Leal, \& Tasker, 2019; Gato et al., 2020a, b, c). Second, compared with most of their heterosexual peers, LGB persons need to rely more on assisted reproduction technologies (ART) or on adoption agencies to access parenthood, in which professionals might gate-keep access (Bergstrom-Lynch, 2016; Tasker \& Bellamy, 2019). In addition, gaining access to ART and adoption services might on itself result in several psychological consequences (Glazer, 2014). Finally, compared with different-sex couples, same-sex couples face a more complex and a longer process of decisionmaking which is initiated when one of them expresses a desire to parent (Goldberg, 2010a, b). For example, in situations of biological parenting (e.g., surrogacy), same-sex couples need to settle that only one parent will be biologically related to the child. Among female couples using insemination, a decision needs to be made regarding who will bear the child (Glazer, 2014) and/or who will be the sperm donor and which role this person will play in the child's life (Goldberg, 2006). Furthermore, in contexts where adoption by same-sex couples is not allowed, only one parent will be recognised as the legal parent (Bauermeister, 2014).

Some studies have documented the association between the transition to parenthood and negative outcomes regarding couple adjustment, mental health, and marital satisfaction (e.g., Goldberg, 2010a, b; Pilkington, Milne, Cairns, Lewis, \& Whelan, 2015). In this regard, similar to heterosexual persons, lesbian women and gay men who became parents reported poor levels of mental health, relationship quality, and sexual satisfaction across the transition to parenthood (Bergman, et al., 2010; Goldberg, 2010a, b; Huebner, Mandic, Mackaronis, Beougher, \& Hoff, 2012; Ross, Steele, Goldfinger, \& Strike, 2007). Support from friends, family, and the workplace seems to buffer against these negative effects (Goldberg et al., 2014a, b). However, social support might also be limited because parenthood is a complex transition and new parents deal with challenging experiences and feelings, with which other persons have difficulties in understanding and empathizing (White, 1976).

\section{LGB Persons and their Social Networks}

There is a long and solid empirical evidence that shows that social support enables coping with crisis and adaptation to change (Cobb, 1976). Classically, House (1981) theorized four types of supportive behaviours considering them as potential forms of social support, namely, (i) emotional support (e.g., empathy, caring, love, trust), (ii) instrumental support (e.g., money, labour, time), (iii) informational support (e.g., providing support for coping with personal and environmental problems), and (iv) appraisal support (e.g., providing affirmation, feedback, social comparison, and self-evaluation). Considering this, a social support network may be defined as a unit of social structure whose ties of support connect persons or groups (Cooke, Rossmann, McCubbin, \& Patterson, 1988).

Social support, such as that provided by parents and other family members, is a key factor in the decision to have children among LGB persons (Sumontha, Farr, \& Patterson, 2016). However, results regarding the role of social support among LGB persons are not consensual. Some studies have indicated that lesbian and gay individuals generally have less supportive family relationships than their heterosexual peers (Leal et al., 2019a, b; Tate $\&$ Patterson, 2019). Nevertheless, when lacking support and acceptance from their families of origin, LGB persons sometimes create new relational networks or "families of choice" (Weston, 1991) which many times become the main social network, even later in life (Wardecker \& Matsick, 2020). Other studies suggest that after becoming parents, lesbian women and gay men report enhanced relational bonds with their own families of origin (Bergman, Rubio, Green, \& Padrón, 2010; Gianino, 2008). At the same time, some studies have reported that LGB persons in the transition to parenthood, and more so gay men, may feel an increasing distance between themselves and the LGBT community (Armesto \& Shapiro, 2011; Gianino, 2008). This gender-specific difference might be associated with the stereotype of the "childless gay man" (Armesto \& Shapiro, 2011) while parenthood is traditionally viewed as a feminine domain (Hicks, 2013; Wall et al., 2007).

Furthermore, when we consider social support, we should take into account the background in terms of laws and social policy. For instance, when same-sex adoption is not allowed, this unsupportive legal context seemed to influence the psychological well-being of future gay parents (Bauermeister, 2014; Russell \& Richards, 2003) as well as the legal protection of the non-biological parent and even the child (Baumle, 2018). Thus, inclusive legal policies to protect LGB parents and their children might be faced as human rights (Santos, Santos, Duarte, \& Lima, 2009) which legalize and protect families (Baumle, 2018).

Overall, the transition to parenthood and the role of social support in this life period are understudied phenomena among LGB persons (Goldberg, 2010a, b). Thus, the aim of the present study was to systematize existing 
knowledge about the role of different types of social support in the transition to parenthood of LGB people.

\section{Method}

We conducted a systematic review of the literature using Preferred Reporting Items for Systematic Reviews and MetaAnalyses (PRISMA) guidelines with a PRISMA checklist (Howie, 2019; Moher, Liberati, Tetzlaff, Altman, $\&$ The PRISMA Group, 2009) (Fig. 1). PRISMA (Howie, 2019; Moher et al., 2009) is a transparent and multifaceted instrument to report systematic reviews because of its characteristics and continuum development which make it relevant to any systematic review (Moher, Liberati, Tetzlaff, \& Altman, 2010). For these reasons, recent systematic reviews focusing on LGBT issues had chosen this review strategy (e.g., Caceres, Travers, Primiano, Luscombe, \& Dorsen, 2020; Layland et al., 2020; Sherman, Clark, Robinson, Noorani, \& Poteat, 2020). This review includes the available studies about the role of social support in the transition to parenthood among LGB persons.

\section{Search Strategy, Databases, and Inclusion and Exclusion Criteria}

This search was conducted in May 2019. Systematic searches were conducted by two independent researchers in seven online databases indexed on Web of Science: MLA Directory of Periodicals, Academic Search Ultimate, Fonte Academica, PsycARTICLES, Psychology and Behavioral Sciences Collection, PsycINFO, and Sociology Source Ultimate. In each of the electronic bases we used the following word combination: *transition to parenthood OR first time parents OR becoming a parent* AND *Igbt OR gay OR homosexual OR lesbian OR bisexual OR transgender OR queer OR sexual minority OR sexual minorities OR lgbtq OR trans OR same-sex* AND *social support OR family support OR community support OR LGBT support OR support OR engagement*. No condition was established regarding the geographical origin of the studies, language, or sample characteristics. After the initial results, duplicated results were automatically removed by the online system. Considering the target population and the importance of
Fig. 1 PRISMA flow diagram

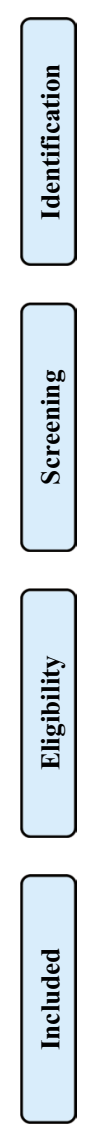

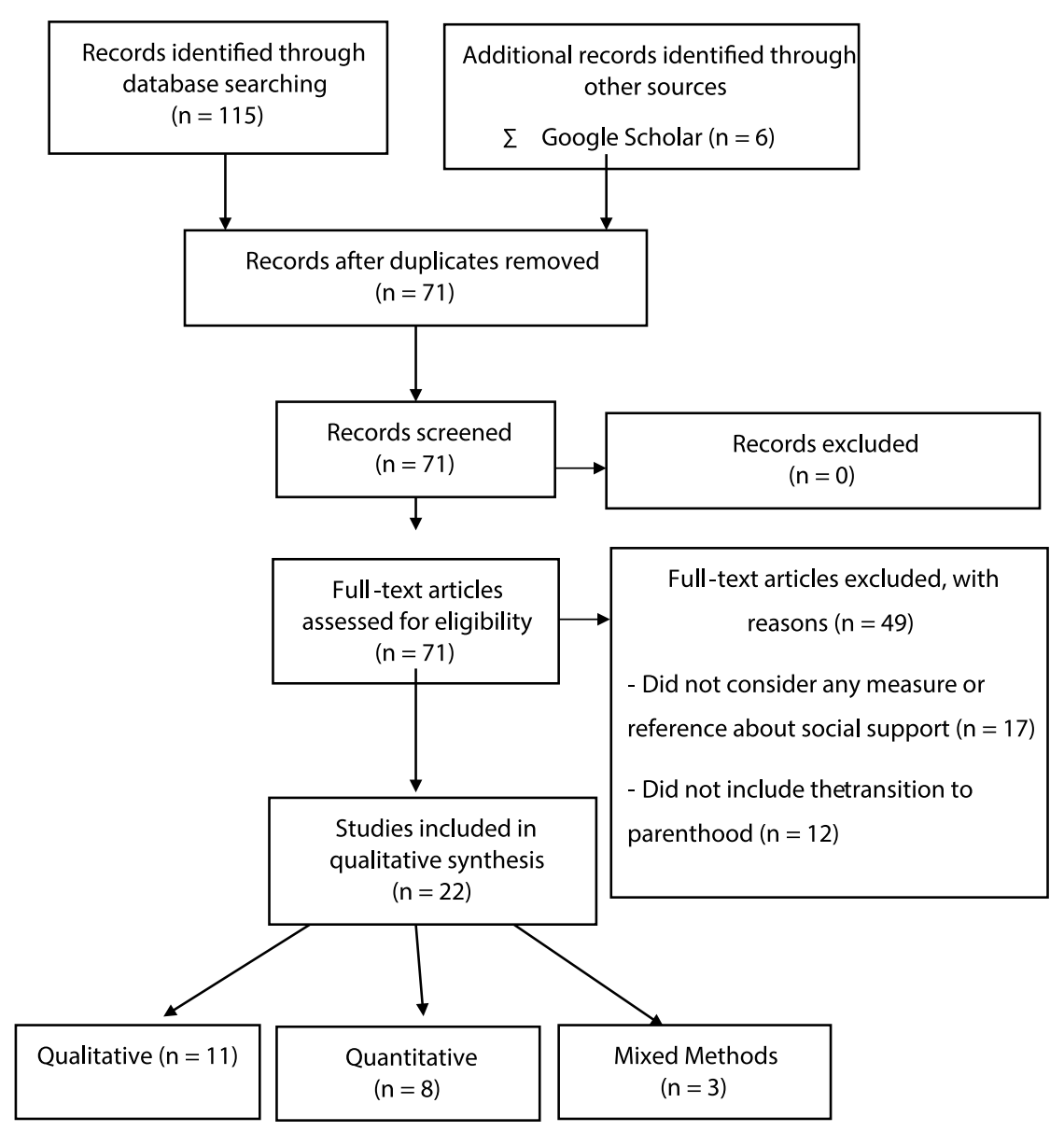


including studies that were not identified in traditional databases, we also used Google Scholar, as it is common in this field research (e.g., Farr, Tasker, Goldberg, 2017; Toomey \& Russell, 2016). Through this last search, six additional articles were identified (Fig. 1). To be included in this systematic review, we established the following criteria: (i) the sample included lesbian, gay, and bisexual persons; (ii) regarding social support each study should have considered, at least, one of these types of support: family support, intergenerational family solidarity, community support, LGBT support, or other forms of social support; (iii) manuscripts should be primary studies; and (iv) manuscripts should have been peer-reviewed. Regarding our criteria, it is important to note three aspects. First, we included trans persons in our sample because they might also identify themselves as LGB. Second, the concept of social support is quite embracing, so, based on our literature review, we tried to use several dimensions that may be applied to LGB population. Third, we considered only peer-reviewed studies, once the review process improves the work quality (Armstrong, 1997; Givoni, 2017). Considering this last standard, theoretical studies, dissertations, and literature reviews were excluded from subsequent analyses.

\section{Procedure}

\section{Data Collection}

We used the Mendeley Reference Manager software to allocate the final chosen articles and their respective references. Then, to ensure compliance with the inclusion criteria, the first two authors read the full articles and decided on the eligibility of the studies to answer the present research interest. Concerning this, a predetermined template was drawn to check: (i) target population (LGB persons), (ii) the mention of transition to parenthood, (iii) the inclusion of social support measures (quantitative instruments or qualitative mentions), (iv) the condition of being a primary study, and (v) the sociodemographic characteristics as sample size, the year the study was conducted, the percentage of LGB participants, and the methodology type for the final 22 studies (Table 1). Initially, 71 articles were selected but after checking our criteria template, only 22 met all the criteria and were included to further qualitative analysis. This process is displayed in flow-chart form in Fig. 1.

\section{Coding of Studies}

The 22 identified studies were published between 2000 and 2018. Please, see Table 1 for a summary of the descriptive information gleaned. Five of the 22 papers were normativecomparative studies and, therefore also included heterosexual persons (Crawshaw \& Montuschi, 2014; Goldberg et al., 2014a, b; Goldberg \& Smith, 2008a, 2014; Lavner et al., 2014). Nine of the studies focused on female samples (Chabot \& Ames, 2004; DeMino, Appleby, \& Fisk, 2007; Dunne, 2000; Goldberg, 2006; Goldberg \& Smith, 2008b; Manley, Goldberg, \& Ross, 2018; Ross et al., 2005), six on male samples (Brinamen \& Mitchell, 2008; Gianino, 2008; Goldberg, Downing, \& Moyer, 2012; Perrin, Pinderhughes, Mattern, Hurley, \& Newman, 2016; Tornello \& Patterson, 2015; Wells, 2011), one of them also included transgender persons (Klittmark et al., 2019), and the remainder included males and females (Brown, Smalling, Groza, \& Ryan, 2009; Crawshaw, \& Montuschi, 2014; Goldberg et al., 2014a, b; Goldberg \& Smith, 2011; Lavner, Waterman, \& Peplau, 2014). Considering a total of 2081 participants, across the 22 papers, 834 persons defined themselves as lesbian women, 1197 as gay men, 30 as bisexual individuals, and 20 as plurisexual, queer, or pansexual. Concerning gender, two persons identified themselves as transgender, three as queer, 877 as women, and 1199 as men. Thus, most of the participants seem to be cisgender and from western countries.

\section{Synthesis of Themes}

In this literature review our aim was to understand the role of different types of social support in the transition to parenthood among LGB persons. After reached the eligible studies, the first two authors identified the main emergent themes across the studies. Next, considering the theoretical approach the codes were sorted into potential themes, and then themes were discussed between the first two authors and the third one. The fourth author played the important role of auditor, and themes were finally stated on a thematic map (Fig. 2). Finally, we systematized the conclusions and findings which had emerged from the studies considering the role of social support in the transition to parenthood among LGB persons.

\section{Differences in Perceived Social Support}

In the transition to parenthood, perceived support seemed to differ as a function of (i) sexual orientation, (ii) gender, and (iii) coming-out status. Among the reviewed articles, two studies (Goldberg \& Smith, 2008a; Lavner et al., 2014) compared the perceived social support among LGB and heterosexual persons. No differences were found considering general social support (Lavner et al., 2014) and support from friends (Goldberg \& Smith, 2008a). Regarding gender, women perceived more support from family and friends, compared with men (Goldberg \& Smith, 2008a). However, lesbian women perceived less support from family than 


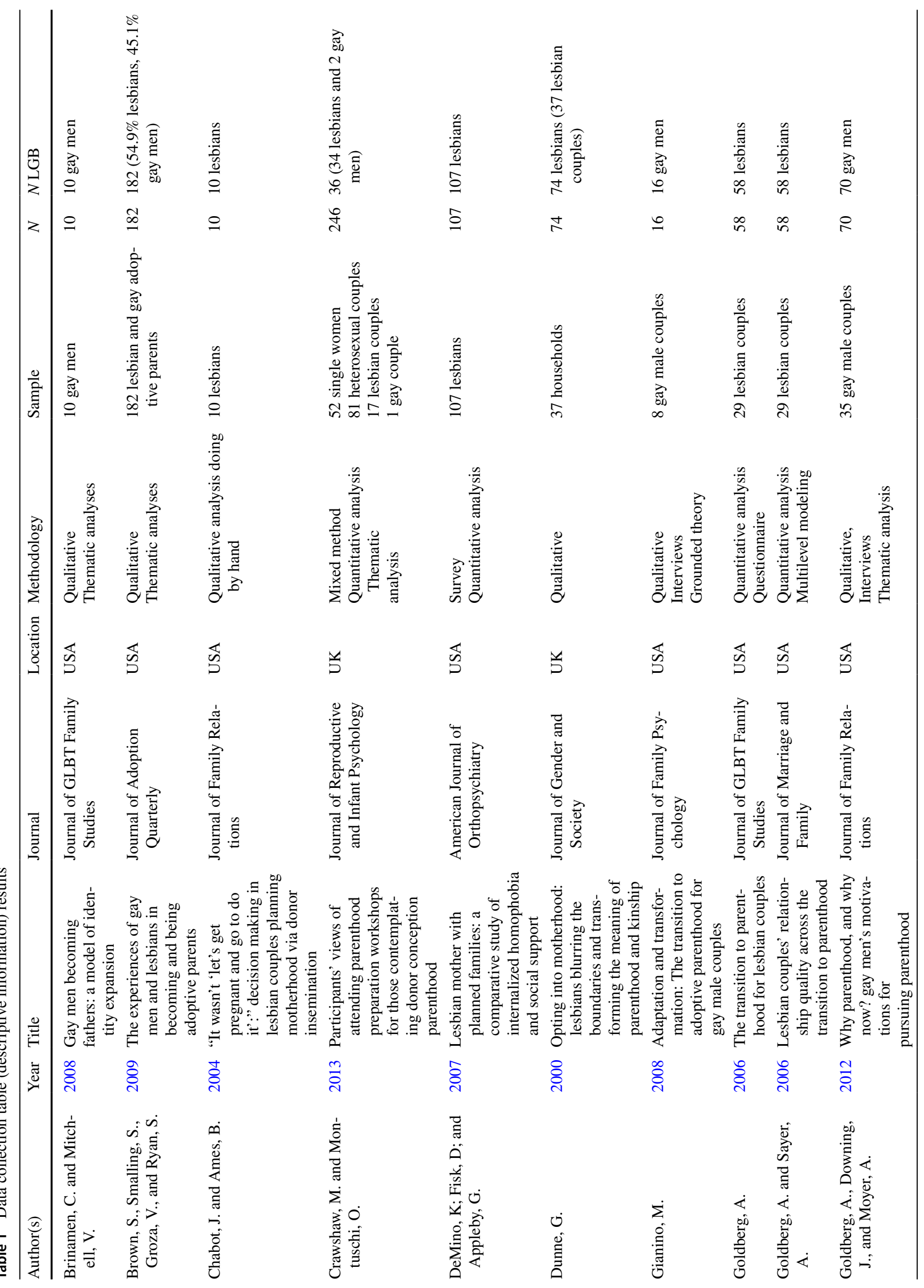




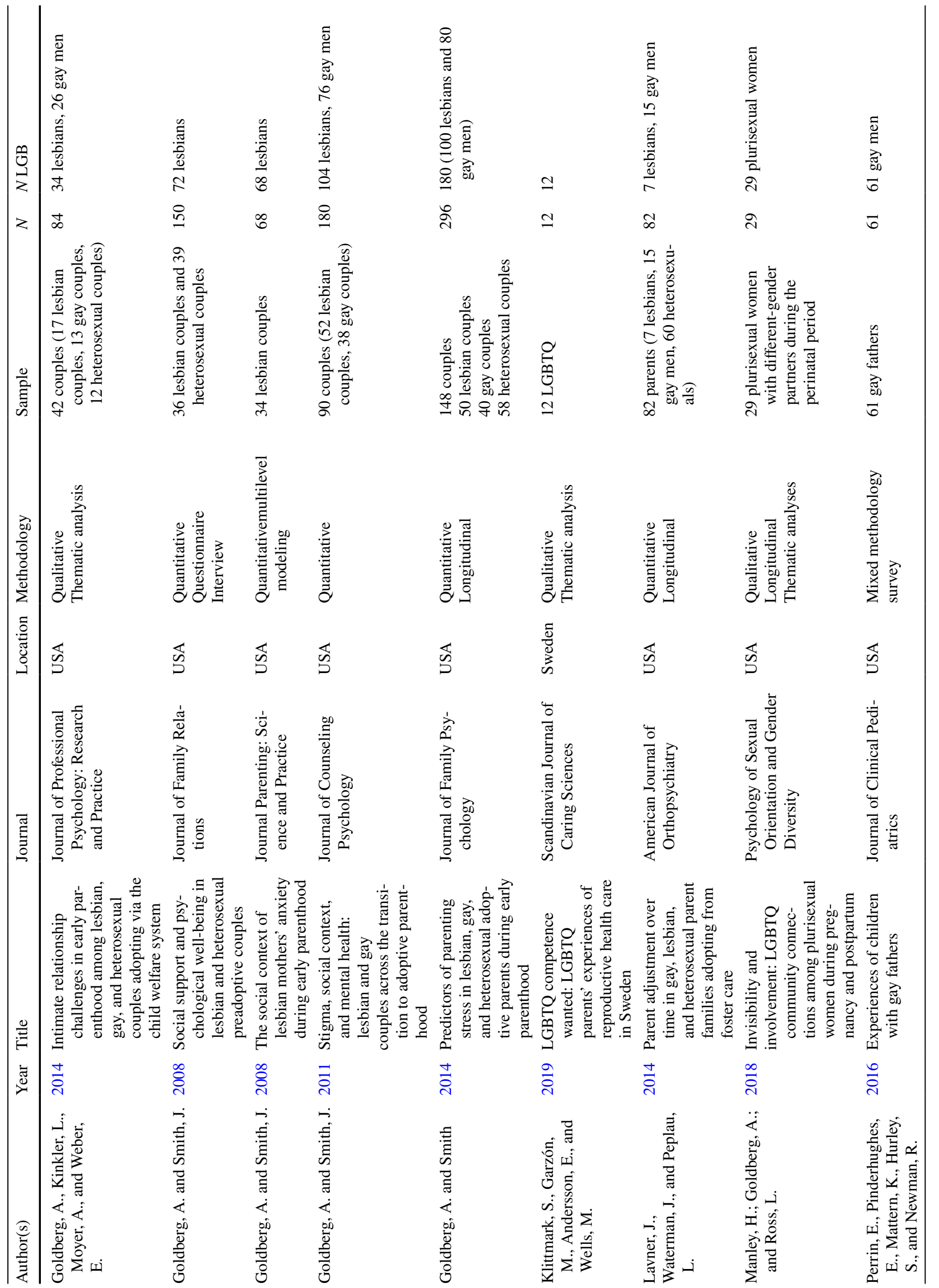


heterosexuals (Goldberg \& Smith, 2008a). Furthermore, gay men who became fathers after coming-out reported more social support than gay men who had not come out (Tornello \& Patterson, 2015).

To understand the role of social support in transition to parenthood, we consider the following sources of support found across the reviewed literature: (i) families of origin, (ii) families of choice, (iii) partners (iv) friends, (v) LGBT community, other LGBT parents, and support groups, (vi) community: neighbourhood, legal context, and schools, and (vii) workplace.

\section{Sources of Support}

\section{Families of Origin}

Both gay and lesbian parents reported support from their families of origin (Brinamen \& Mitchell, 2008; Brown et al., 2009; DeMino et al., 2007; Dunne, 2000; Gianino, 2008; Goldberg, 2006; Goldberg \& Smith, 2011; Perrin et al., 2016; Ross et al. 2005; Wells, 2011). This type of support increased across the transition to parenthood (Brinamen \& Mitchell, 2008; Brown et al., 2009; Goldberg, 2006; Goldberg \& Smith, 2011), even when the family of origin was not initially supportive of the decision to have children (Brown et al., 2009; Ross et al., 2005) or at the moment of comingout (Gianino, 2008; Wells, 2011). One study reported that relational ties were also enhanced with the extended family (Wells, 2011).

However, some LGB parents felt a lack of support from their own family of origin (Brown et al., 2009; Ross et al., 2005; Wells, 2011) and from their partner's family (Brown et al., 2009; Perrin et al., 2016). Lesbian women who were considering pregnancy felt a lack of support from their families of origin, including their extended families (Goldberg, 2006; Ross et al., 2005). At the beginning of parenting plans, some grandparents-to-be put forward moral objections to same-sex parenthood (Ross et al., 2005). Also, in the case of lesbian women who were already mothers, some families considered that the non-biological mother was not a "real mother" (Ross et al., 2005). Considering the lack of support from families of origin, if non-biological mothers expected an unmet level of support from their partners' family, then non-biological mothers-to-be tended to report increased conflict with partners and their respective family, because of dashed expectations (Goldberg \& Sayer, 2006). In turn, some gay men also faced prejudice from their parents who did not support parenting projects because this implied further acknowledgement that their sons were definitely not heterosexual men (Wells, 2011).

Sometimes anticipated stigma upon parenthood was not actually experienced after having children. Gay men who did not anticipate support from families and friends 
Fig. 2 Thematic map

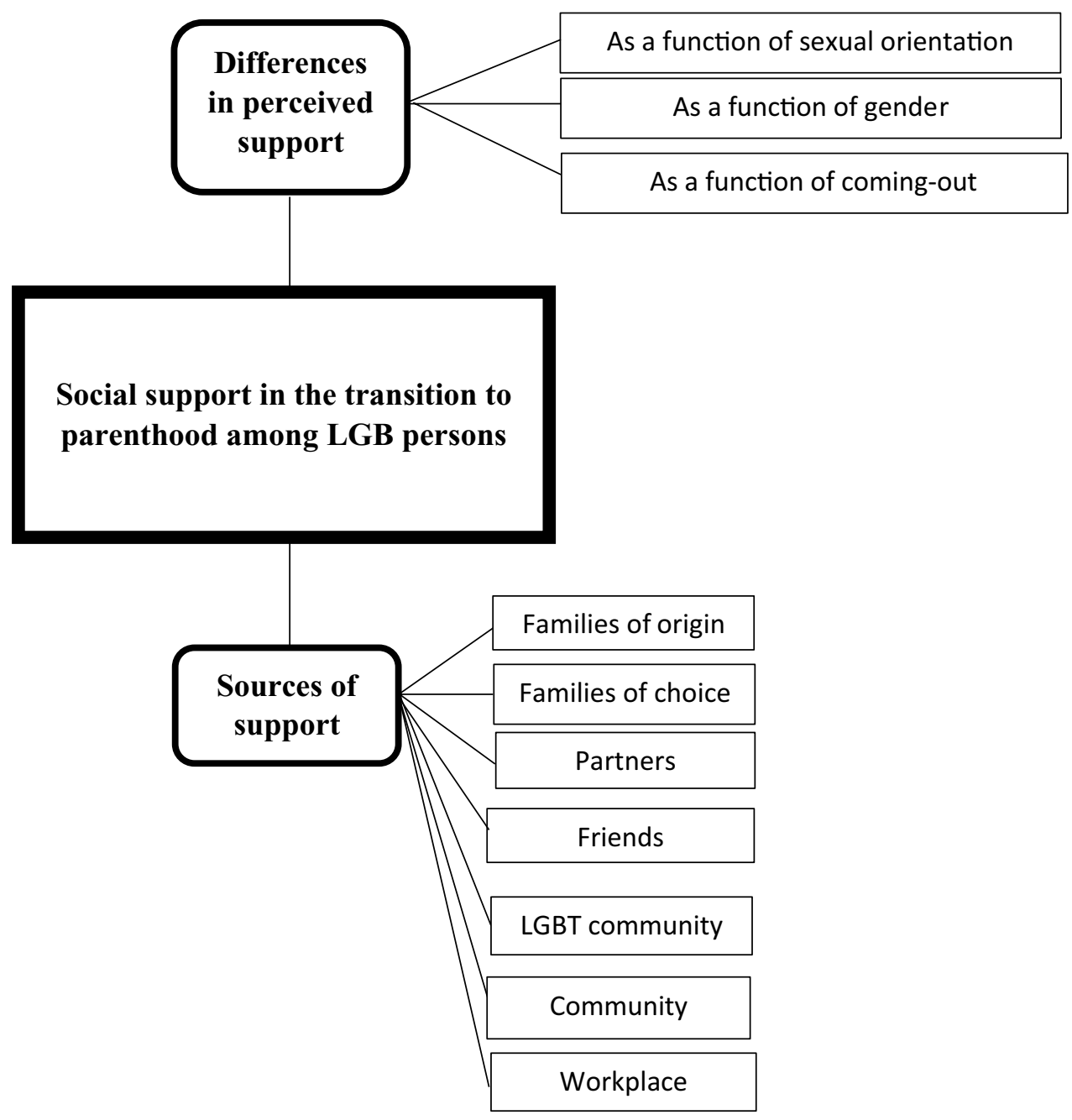

before parenthood received higher levels of support from these sources than they had expected (Brown et al., 2009; Gianino, 2008). Nevertheless, gay men still feared the possible stigma that their children might face from family, friends, school, or society because of their own sexual orientation (Brown et al., 2009; Gianino, 2008).

\section{Families of Choice}

Regarding families of choice, Brinamen and Mitchell (2008) conceptualized a model of gay male identity that included the process through which couples become parents. In this regard, the authors mentioned how these men valued a definition of family which considered emotional relationships and not necessarily traditional biological ties. Understanding the concept of family of choice seemed to be a turning point for gay men in considering parenthood as a viable option because they became aware of having a wide and supportive network to help them in this life stage (Brinamen \& Mitchell, 2008).

\section{Partners}

Among the reviewed studies, partners were mentioned in one study as a valuable source of support (Tornello \& Patterson, 2015). In this study, when a gay male parent had a partner, this was associated with higher levels of perceived social support and self-disclosure in parenthood. Regarding lesbian couples, some differences were found in social support as a function of the biological tie with the child, with biological mothers receiving more support than nonbiological mothers (DeMino et al., 2007; Goldberg \& Sayer, 2006; Goldberg \& Smith, 2008b). For the latter, perceived instrumental support influenced anxiety: when these women perceived less support in prenatal period, their anxiety levels increased across the transition to parenthood. Interestingly, perceived emotional support did not influence 
non-biological mothers' anxiety. In this regard, Goldberg and Smith (2008b) explained their results by considering the role of non-biological mothers during the transition to parenthood: usually, non-biological mothers are working to provide instrumental support to their families. Thus, for these women, the received and the given instrumental support might be more important than emotional support at the time of transition (Goldberg \& Smith, 2008b).

Our systematic review also highlighted differences between biological and non-biological mothers in expectations of social support. Non-biological mothers who had greater support expectations than what was received from their partner's family during this transition, tended to report increased conflict in their couple relationship and in their relationship with the partner's family upon entry into parenthood (Goldberg \& Sayer, 2006).

Lesbian biological mothers reported lower levels of support from their friends than lesbian non-biological mothers (DeMino et al., 2007). Furthermore, biological mothers seemed to rely more on family support and less on friends and LGBT community support than non-biological mothers (DeMino et al., 2007). Considering these results, lesbian biological mothers were more similar to heterosexual mothers regarding their social support expectations, than to lesbian non-biological mothers (DeMino et al., 2007).

\section{Friends}

Both LGB and heterosexual friends were named as a substantial source of support for parenthood (Dunne, 2000; Goldberg, 2006; Goldberg \& Smith, 2011; Perrin et al., 2016). Specifically, heterosexual friends seemed to reinforce their relationship with LGB persons during the transition to parenthood (Dunne, 2000). Compared with family, friends were sometimes perceived as more supportive (Goldberg, 2006; Goldberg $\&$ Smith, 2011). In this regard, despite having no influence in depressive symptoms, higher levels of perceived support from friends predicted lower levels of anxiety (Goldberg \& Smith, 2011). However, some participants also reported a lack of support from friends (Brown et al., 2009; Goldberg, 2006; Gianino, 2008). Sometimes, when friends were very supportive at the beginning, their support decreased over the transition to parenthood (Goldberg, 2006). In the case of heterosexual friends, some lesbian and gay participants reported that some of this support network detached, namely, those who argued that they could accept their sexual orientation, but that parenting was beyond their "tolerance" threshold (Brown et al, 2009). Some studies suggest that LGB friends were perceived as more open-minded than heterosexual friends about some childcare topics (e.g., breastfeeding), thus enhancing the well-being of first-time plurisexual mothers (Manley et al., 2018). In this regard, gay and lesbian parents saw other LGBQ women who are mothers, or those in the transition to parenthood, as role models (Ross et al., 2005). Even when lesbian and gay friends did not want to be parents, participants perceived general support from the LGBT community (Brinanen \& Mitchell, 2008; Dunne, 2000). Some also strengthened their relational ties, particularly with lesbian friends who could define themselves as "lesbian aunties" (Dunne, 2000). In turn, when lesbian women became pregnant from gay friends as donors, they reported donors as emotionally supportive in both the transition to parenthood and subsequently during parenthood too. Furthermore, lesbian mothers often sought to involve known donors in parenting (Dunne, 2000).

Nevertheless, some participants reported worse reactions from lesbian and gay friends than from heterosexual friends, which is in line with the stereotype that being LGB is not reconcilable with being a parent is still prevalent in the LGBT community (Brown et al., 2009; Gianino, 2008; Manley et al., 2018; Ross et al., 2005).

\section{LGBT Community, Other LGBT Parents, and Support Groups}

In several reviewed studies, the LGBT community was mentioned as an important and positive source of support (Brinanen \& Mitchell, 2008; Chabot \& Ames, 2004; Crawshaw \& Montuschi, 2014; Dunne, 2000; Goldberg et al., 2014a, b; Manley et al., 2018; Ross et al., 2005; Wells, 2011). In this regard, support groups that included other LGB parents were mentioned as a great help (Brinanen \& Mitchel, 2008; Chabot \& Ames, 2004; Crawshaw \& Montuschi, 2014; Dunne, 2000; Goldberg et al., 2014a, b; Manley et al., 2018; Ross et al., 2005; Wells, 2011). In these support groups and parenting preparation workshops, LGB parents in the transition to parenthood felt they could discuss some specificities of LGB parenthood (Goldberg et al., 2014a, b), find resources to pursue ART interventions, and learn how to manage their different social support networks (Crawshaw \& Montuschi, 2014). However, a lack of support and a consequent detachment from the LGBT community as parents, or as future parents, was also reported by a considerable number of LGB participants across various studies (Brown et al., 2009; Chabot \& Ames, 2004, Dunne, 2000; Gianino, 2008; Goldberg et al., 2014a, b; Klittmark et al., 2019; Manley et al., 2018; Perrin et al., 2016; Ross et al., 2005). LGB persons in transition to parenthood claimed the support and presence of other LGB persons in parenting support groups but also complained they were often unavailable to participate in these events (Goldberg et al., 2014a, b; Klittmark et al., 2019). Although some LGB participants considered that parenting support groups without LGB parents were not useful (Goldberg et al., 2014a, b), other participants found these groups a source of emotional support even when they were just composed of heterosexual persons (Manley et al., 2018). 
The perceived lack of support from the LGBT community seemed to increase across the transition to parenthood (Brown et al., 2009), expressed by feelings of rejection (Manley et al., 2018), and a lack of LGBT places and events to go with children (Ross et al., 2005). Specifically, in the case of gay men, parenthood was not seen as part of gay identity (Gianino, 2008). In the case of bisexual women, they felt detached and excluded from the LGBT community if they become mothers with a male partner (Manley et al., 2018).

\section{Community: Neighbourhood, Legal Context, Human Services, and Schools}

A sizeable number of participants reported a lack of support from neighbourhood and their religious community (Perrin et al., 2016). Furthermore, when neighbourhoods were not perceived as gay-friendly, participants also reported more depressive symptoms (Perrin et al., 2016). This lack of community support was also associated with increased levels of internalized homophobia across the transition to adoptive parenthood (Goldberg \& Smith, 2011). Note that internalized homophobia is an intrapsychic conflict based on negative feelings as guilt, shame, anger, hate, and compromises the psychological well-being of these persons (Herek, 2004). However, for other participants, embracing a parental project seemed to be related to receiving more support from the community (Brinamen \& Mitchell, 2008; Perrin et al., 2016; Ross et al., 2005). Thus, neighbours could emerge as a great source of support (Ross et al., 2005) predicting enhanced psychological well-being and fewer depressive symptoms among lesbian and gay couples across the transition period (Goldberg \& Smith, 2011).

The legal context was mentioned in one study as a source of support to LGB parents across the transition to parenthood (Ross et al., 2005). The authors highlighted the importance of health insurance plan to covering costs associated with ART. Furthermore, when considering parenthood benefits, parental leave for non-biological mothers in lesbian couples were listed as a source of legal support. Conversely, lack of available structures to support and recognise same-sex families was identified as a problem (Brown et al., 2009; Wells, 2011) legally and culturally. Specifically, in areas where same-sex adoption is not allowed and only one parent is legally recognised, the parenting role of the other parent can be undermined (Brown et al., 2009; Wells, 2011). Furthermore, parents anticipated that the absence of legal support for their children would jeopardize social security payments and parenting roles, if something happened to the legal parent (Brown et al., 2009).

Professional and voluntary support service agencies were mentioned once as a source of support during the transition to parenthood (Chabot \& Ames, 2004). This type of support was considered a valuable resource in accessing further help and in connecting prospective parents, providing information about the adoption process and other important resources. Nevertheless, studies also highlighted the lack of support both from adoption agencies (Brown et al., 2009) and reproductive healthcare services (RHS) (Klittmark et al., 2019). Specifically, some adoption agencies expressed high levels of prejudice against same-sex parenthood. In dealing with RHS, LGB persons encountered a heteronormative approach and reported a lack of information about LGB specificities (e.g., conception, gender stereotypes). This heteronormative approach provoked anxiety and negative expectations. In order to cope with this situation, LGB persons either hid their sexual orientation, adopted as single persons, and/or looked for additional information via the internet, social media, and their friends (Klittmark et al., 2019).

Looking into future LGB parenthood, prospective parents reported, in the USA, that school services seemed non-supportive for LGB parents. LGB prospective parents thought it would be difficult to find an inclusive pre-school and school institution where having two dads or moms was not seen as disadvantageous to the child (Brown et al., 2009).

\section{Workplace}

Goldberg (2006) highlighted the importance of implementing workplace policies, such as domestic partnership and parental leave benefits, for lesbian couples and same-sex parent families who lacked statutory recognition. In a subsequent study, Goldberg and Smith (2011) found that workplace support was associated with LGB parents reporting fewer anxiety and depression symptoms. Thus, workplace family-friendly policies seem to contribute to positive mental health outcomes of lesbian and gay workers, particularly at a vulnerable life period such as the transition to parenthood.

\section{Discussion}

In this review, we aimed to understand the role of social support in the transition to parenthood among LGB persons. Concurrently, we intended to explore the sources, the needs, and the demands in terms of social support of LGB persons at this life cycle transition.

Support both from family and friends predicted lower levels of parenting stress (Goldberg \& Smith, 2014), and the support received from friends buffered against anxiety and depression (Goldberg \& Smith, 2011). Although family and friends were identified as important sources of support (Brinamen \& Mitchell, 2008; Brown et al., 2009; DeMino et al., 2007; Dunne, 2000; Gianino, 2008; Goldberg, 2006; Goldberg \& Smith, 2011; Perrin et al., 2016; Ross et al., 
2005; Wells, 2011), these networks were also often reported as unsupportive (Brown et al., 2009; Chabot \& Ames, 2004, Dunne, 2000; Gianino, 2008; Goldberg et al., 2014a, b; Klittmark et al., 2019; Manley et al., 2018; Perrin et al., 2016; Ross et al., 2005; Wells, 2011). This ambivalence may put LGB individuals in a vulnerable situation during their transition to parenthood. Specifically, because of stereotypes about their sexual identity, gay men are sometimes perceived as unable to parent (Brown et al., 2009; Gianino, 2008). In turn, bisexual persons feel a detachment from both LGBT community and friends when they parent within a heterosexual relationship (Manley et al., 2018) and it is understudied how bisexual parents experience family of origin support during this life cycle period.

As parents, women showed higher levels of perceived social support than men, regardless of their sexual orientation. Lesbian women seemed to engage family support to adapt themselves to the increased stress during motherhood (DeMino et al., 2007). Still concerning lesbian mothers, the challenges during the transition to parenthood seemed to vary as a function of their biological tie with children (DeMino et al., 2007; Goldberg \& Sayer, 2006; Goldberg \& Smith, 2008a, b). Lesbian biological mothers reported higher levels of support and trust in the family, whereas lesbian non-biological mothers relied more on friends' support (Goldberg \& Smith, 2014). Thus, lesbian biological mothers seem to be more similar to heterosexual women who also showed higher levels of confidence in the family than in friends (DeMino et al., 2007). Furthermore, lesbian biological mothers appear to benefit more from receiving emotional support (e.g., dialogue, visits), whereas lesbian non-biological mothers indicate a preference for receiving instrumental support (e.g., money, childcare) (Goldberg \& Smith, 2008a, b). This difference might happen because non-biological mothers have to work outside and provide financial support to the family, whereas biological mothers tend to take on more of the childcare. Because of this, nonbiological mothers might be more sensitive than biological mothers to the availability of friends and other persons outside the family, who can help with the childcare (e.g., babysit) and, thus supplement or replace the non-biological mothers' expected contribution to child care (Goldberg \& Smith, 2008a, b). These differences related to the biological tie with the child might be a valuable piece of information to psychological services in order to adapt support interventions to a same-gender couple. Considering these results, we need to take into account both sexual orientation, gender, and the biological tie with the child when analysing the role of social support during the transition to parenthood.

In turn, the perception of an inclusive legal context (Bauermeister, 2014; Brown et al., 2009; Gianino, 2008) was associated with the anticipation of reduced stigma upon parenthood (Brown et al., 2009; Gianino, 2008). For instance, when only one parent is legally recognized, the child and the other parent are unprotected by the legal system, which can foster anxiety. Additionally, the invisibility of a parenting role negatively influences both the psychological wellbeing of LGB parents and also LGB prospective parents (Bauermeister, 2014; Brown et al., 2009; Gianino, 2008). Therefore, the legal rights of LGB parents (and prospective parents) and their children, as well as their psychological well-being, should be ensured by state laws and policies.

Generally, relationships of LGB parents with their families of origin seem to be enhanced upon parenthood (Brinamen \& Mitchell, 2008; Brown et al., 2009; DeMino et al., 2007; Dunne, 2000; Gianino, 2008; Goldberg, 2006; Goldberg \& Smith, 2011; Perrin et al., 2016; Ross et al., 2005; Wells, 2011), even when a previous breach was reported upon coming-out (Gianino, 2008; Wells, 2011). Intriguingly, even when grandparents and other family members raised moral objections to the plan of having children, support from family of origin also increased during the transition to parenthood (Brown et al., 2009; Goldberg, 2006; Ross et al., 2005). This is an important information for human service professionals when helping LGB parents manage their expectations regarding different sources of support at different stages in the transition to parenthood.

The LGBT community is often an important source of social support for sexual and gender minority individuals, especially when families of origin are not available (Weston, 1991). However, this community sometimes has difficulties in accepting parenthood as a part of a LGB identity (Brown et al., 2009; Chabot \& Ames, 2004, Dunne, 2000; Gianino, 2008; Goldberg et al., 2014a, b; Klittmark et al., 2019; Manley et al., 2018; Perrin et al., 2016; Ross et al., 2005). Furthermore, LGB parents rarely seem a readily accessible group to help and act as role models for other LGB parents or future parents (Goldberg et al., 2014a, b; Klittmark et al., 2019), even if having other LGB parents in parenting support groups was an aspiration of some participants (Goldberg et al., 2014a, b; Klittmark et al., 2019; Wells, 2011). This finding is particularly relevant for professionals working with LGB persons in adoption agencies, social security services, and ARS as these agencies might be in a privileged position to assist in fostering supportive relationships among LGB parents (Goldberg et al., 2014a, b; Klittmark et al., 2019; Wells, 2011).

A supportive workplace environment was also associated with fewer anxiety and depression symptoms expressed by lesbian and gay parents (Goldberg \& Smith, 2011). Thus, specific labour policies to protect LGB parents through their transition to parenthood are necessary to promote the psychological well-being and the financial support of LGB parents who work (Fidas \& Cooper, 2018; Pichardo et al., 2019). 
Fig. 3 Thematic map considering House's (1981) types of supportive behaviour

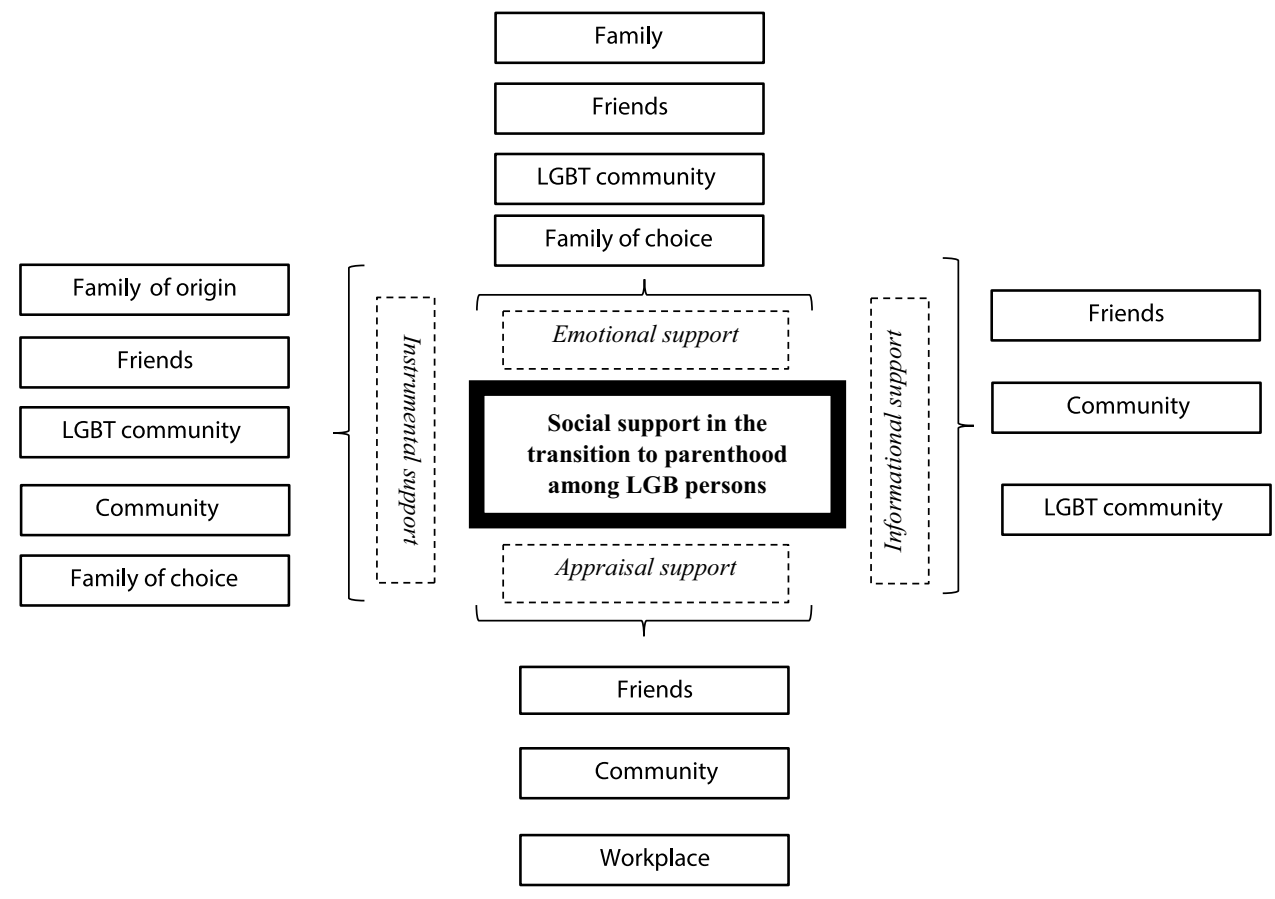

Lastly, we highlight avenues for research projects. First, although the transition to parenthood is an important extensively researched life stage (Nelson et al., 2014; Pilkington et al., 2015), studies including LGB samples are still scarce. Second, among LGB persons, bisexual persons appear to face specific challenges, such as being stigmatized within LGBT community when they experience parenthood within a different-sex relationship (Manley et al., 2018). However, an examination of the reviewed studies, indicated that bisexual parents-to-be are underrepresented. Thus, samples of bisexual persons are needed and deserve special attention (Barker et al., 2012; Tasker \& Delvoye, 2015). Third, non-biological parents or parents who are not legally recognised faced additional legal and supportive challenges which might be considered across the transition to parenthood. Fourth, as we have noticed, the support from friends, LGBT community, and family fluctuates and changes over the transition to parenthood. Thus, longitudinal studies are needed to understand the transition to parenthood and how to promote support resources during this process. Given the importance of legal context, when there are legal changes concerning LGBT rights, longitudinal studies are also crucial to understand the impact of these changes on the cohorts concerned. Lastly, social support has been studied but there is a lack of consistent definitions and operationalization (Sarason et al., 1987). This had difficult the systematization of studies including social support as a variable. Thus, future studies should understand this caveat and provide more empirical consistence and a more rigorous assessment of social support. 


\section{Conclusion}

This review systematizes current knowledge concerning the role of social support during the transition to parenthood among LGB persons, highlighting key issues with important implications for clinical, community, social, and political interventions. This type of work is crucial to address the main concerns of the well-being of LGB persons (Barbot \& Durso, 2017). First, there is an urgent need for research with lesbian women, gay men, and bisexual persons, to understand their specific needs across the transition to parenthood. In this regard, confront academia with the implicit heteronormativity of its studies (Paternotte, 2018) is necessary to promote more inclusive studies regarding sexual identity. Furthermore, human services and clinical professionals working with LGB parents and future parents occupy privileged positions that could enhance the support networks of these persons. In turn, these professionals must acknowledge the processes through which family of origin members provide support to their LGB members at different points along the transition to parenthood pathway. In turn, legal and political concerns are also raised once unequal legal landscapes negatively affects LGB persons and their families' well-being (Kazyak \& Woodell, 2016). Parentalleaves, health security insurance, and parental protection laws are needed to guarantee the rights of LGB parents and their children. Even when adoption rights and access to ART are legal, it is important to consider this does not mean that LGB parenting rights are assured (Santos, 2004). In this regard, is necessary to continually provide training concerning LGB parenting to human services (e.g., medical professionals, psychologists, and social assistants) (Gato et al., 2020a, b, c; Gato \& Fontaine, 2017; Goldberg et al., 2009). Concerning the workplace, inclusive environments, training, team building activities, and labour laws are urgent to make LGB parents feel safe to come out and, consequently, exercise their parental rights (e.g., parental leave) (Fidas \& Cooper, 2018; Pichardo et al., 2019; Vasquez del Aguila \& Cantillon, 2010). Finally, schools seemed to be a source of worry for LGB parents and LGB parents-to-be. Thus, educational policies should promote inclusive school curriculums, teacher and school staff training for LGBTI issues, and local strategies (Gato et al., 2020a, b, c).

Overall, the promotion of the availability of different sources of support to LGB parents during their transition to parenthood will enhance the psychological well-being of parents and parents-to-be ultimately contributing to a more egalitarian society where parenthood is a universal human choice free of prejudice and discrimination.

\section{References}

Armstrong, J. S. (1997). Peer review for journals: Evidence on quality control, fairness, and innovation. Science and Engineering Ethics, 3(1), 63-84. https://doi.org/10.1007/s11948-997-0017-3

Armesto, J. C., \& Shapiro, E. R. (2011). Adoptive gay fathers: Transformations of the masculine homosexual self. Journal of GLBT Family Studies, 7(1-2), 72-92. https://doi.org/10.1080/1550428X.2011. 537202

Barker, M., Yockney, J., Richards, C., Jones, R., Bowes-Catton, H., \& Plowman, T. (2012). Guidelines for researching and writing about bisexuality. Journal of Bisexuality, 12(3), 376-392. https://doi. org/10.1080/15299716.2012.702618

Baumle, A. K. (2018). The practice of law with LGBT-parent families. Family Court Review, 56(3), 423-433. https://doi.org/10.1111/ fcre. 12358

Bergman, K., Rubio, R. J., Green, R. J., \& Padrón, E. (2010). Gay men who become fathers via surrogacy: The transition to parenthood. Journal of GLBT Family Studies, 6(2), 111-141. https://doi. org/10.1080/15504281003704942

Baiocco, R., \& Laghi, F. (2013). Sexual orientation and the desire and intention to become parents. Journal of Family Studies, 19(1), 90-98. https://doi.org/10.5172/jfs.2013.19.1.90

Barbot, O., \& Durso, L. E. (2017). Promoting a policy and research agenda to protect lesbian, gay, bisexual, and transgender health in the new political era. LGBT Health, 4(4), 241-243. https://doi. org/10.1089/lgbt.2017.0130

Bauermeister, J. A. (2014). How statewide LGB policies go from "under our skin" to "into our hearts": fatherhood aspirations and psychological well-being among emerging adult sexual minority men. Journal of Youth and Adolescence, 43(8), 1295-1305. https:// doi.org/10.1007/s10964-013-0059-6

Bergstrom-Lynch, C. (2016). Lesbians, gays, and bisexuals becoming parents or remaining childfree: Confronting inequalities. New York: Lexington Books.

Bigner, J. J. (2006). Parent-child relations: An introduction to parenting (7th ed.). Upper Saddle River, NJ: Prentice Hall.

Brinamen, C. F., \& Mitchell, V. (2008). Gay men becoming fathers: A model of identity expansion. Journal of GLBT Family Studies, 4(4), 521-541. https://doi.org/10.1080/15504280802191772

Brown, S., Smalling, S., Groza, V., \& Ryan, S. (2009). The experiences of gay men and lesbians in becoming and being adoptive parents. Adoption Quarterly, 12(3-4), 229-246. https://doi. org/10.1080/10926750903313294

Caceres, B. A., Travers, J., Primiano, J. E., Luscombe, R. E., \& Dorsen, C. (2020). Provider and LGBT individuals' perspectives on LGBT issues in long-term care: A systematic review. The Gerontologist, 60(3), 169-183. https://doi.org/10.1093/geront/gnz012

Chabot, J. M., \& Ames, B. D. (2004). "It wasn't 'let's get pregnant and go do it':" Decision making in lesbian couples planning motherhood via donor insemination. Family Relations, 53(4), 348-356. https://doi.org/10.1111/j.0197-6664.2004.00041.x

Cobb, S. (1976). Social support as a moderator of life stress. Psychosomatic Medicine, 38(5), 300-314. https://doi.org/10.1097/00006842197609000-00003

Cooke, B. D., Rossmann, M. M., McCubbin, H. I., \& Patterson, J. M. (1988). Examining the definition and assessment of social support: A resource for individuals and families. Family Relations, 37(2), 211-216. https://doi.org/10.2307/584322

Crawshaw, M., \& Montuschi, O. (2014). It 'did what it said on the tin'-Participant's views of the content and process of donor conception parenthood preparation workshops. Human Fertility, 17(1), 11-20. https://doi.org/10.3109/14647273.2014.881562 
DeMino, K. A., Appleby, G., \& Fisk, D. (2007). Lesbian mothers with planned families: A comparative study of internalized homophobia and social support. American Journal of Orthopsychiatry, 77(1), 165-173. https://doi.org/10.1037/0002-9432.77.1.165

Dunne, G. A. (2000). Opting into motherhood: Lesbians blurring the boundaries and transforming the meaning of parenthood and kinship. Gender \& Society, 14(1), 11-35. https://doi. org/10.1177/089124300014001003

Farr, R. H., Tasker, F., \& Goldberg, A. E. (2017). Theory in highly cited studies of sexual minority parent families: Variations and implications. Journal of Homosexuality, 64(9), 1143-1179. https://doi.org/10.1080/00918369.2016.1242336

Farr, R. H., \& Tornello, S. L. (2016). The transition to parenthood and early child development in families with same-sex parents. International Journal of Birth and Parent Education, 3(3), 17-22.

Fidas, D., \& Cooper, L. (2018). A workplace divided: understanding the climate for $L G B T Q$ workers nationwide. Washington, DC: Human Rights Campaign.

Gato, J., Rangel Henriques, M., \& Leal, D. (2020). Adoption by Lesbian Women and Gay Men: Perceived Challenges and Training Needs for Professionals in Portugal. Adoption Quarterly, 1-24. https://doi.org/10.1080/10926755.2020.1834044

Gato, J., Leal, D., \& Tasker, F. (2019). Parenting desires, parenting intentions, and anticipation of stigma upon parenthood among lesbian, bisexual, and heterosexual women in Portugal. Journal of Lesbian Studies, 23(4), 451-463. https://doi.org/10.1080/10894160. 2019.1621733

Glazer, D. (2014). LGBT transitions to parenthood. Journal of Gay \& Lesbian Mental Health, 18(2), 213-221. https://doi. org/10.1080/19359705.2014.883668

Gato, J., Leal, D., Coimbra, S., \& Tasker, F. (2020). Anticipating parenthood among lesbian, gay, bisexual, and heterosexual young adults without children in Portugal: Predictors and profiles. Frontiers in Psychology, 11, 1058. https://doi.org/10.3389/fpsyg. 2020.010583

Gato, J., \& Fontaine, A. M. (2017). Predicting attitudes toward lesbian and gay parent families among portuguese students from helping professions. International Journal of Sexual Health, 29(2):187201. https://doi.org/10.1080/19317611.2016.1268232

Gato, J., Leal, D., Moleiro, C., Fernandes, T., Nunes, D., Marinho, I., \& Freeman, C. (2020). "The worst part was coming back home and feeling like crying": Experiences of lesbian, gay, bisexual and trans students in portuguese schools. Frontiers in Psychology, 10, 2936. https://doi.org/10.3389/fpsyg.2019.02936

Gianino, M. (2008). Adaptation and transformation: The transition to adoptive parenthood for gay male couples. Journal of GLBT Family Studies, 4(2), 205-243. https://doi.org/10.1080/15504280802096872

Givoni, M. (2017). Why review? Transport Reviews, 37(1), 1-3. https:// doi.org/10.1080/01441647.2017.1230169

Goldberg, A. E. (2006). The transition to parenthood for lesbian couples. Journal of GLBT Family Studies, 2(1), 13-42. https://doi. org/10.1300/J461v02n01_02

Goldberg, A. E., Downing, J. B., \& Richardson, H. B. (2009). The transition from infertility to adoption: Perceptions of lesbian and heterosexual couples. Journal of Social and Personal Relationships, 26(67), 938-963. https://doi.org/10.1177/0265407509345652

Goldberg, A. E. (2010a). From partners to parents: The transition to parenthood for lesbians and gay men. In A. E. Goldberg (Ed.), Lesbian and gay parents and their children: Research on the family life cycle (pp- (pp. 49-88). Washington, DC: American Psychological Association.

Goldberg, A. E., Downing, J. B., \& Moyer, A. M. (2012). Why parenthood, and why now? Gay men's motivations for pursuing parenthood. Family Relations, 61(1), 157-174. https://doi.org/10.1111/j. 1741-3729.2011.00687.x
Goldberg, A. E, Gartrell, N. K, \& Gates, G. J. (2014). Research report on LGB-parent families. UCLA: The Williams Institute. Retrieved from https://escholarship.org/uc/item/7gr4970w

Goldberg, A. E., Kinkler, L. A., Moyer, A. M., \& Weber, E. (2014). Intimate relationship challenges in early parenthood among lesbian, gay, and heterosexual couples adopting via the child welfare system. Professional Psychology: Research and Practice, 45(4), 221. https://doi.org/10.1037/a0037443

Goldberg, A. E., \& Sayer, A. (2006). Lesbian couples' relationship quality across the transition to parenthood. Journal of Marriage and Family, 68(1), 87-100. https://doi.org/10.1111/j. 1741-3737.2006.00235.x

Goldberg, A. E., \& Smith, J. Z. (2008). Social support and psychological well-being in lesbian and heterosexual preadoptive couples. Family Relations, 57(3), 281-294. https://doi.org/10. 1111/j.1741-3729.2008.00500.x

Goldberg, A. E., \& Smith, J. Z. (2008b). The social context of lesbian mothers' anxiety during early parenthood. Parenting: Science and Practice, 8(3), 213-239. https://doi.org/10.1080/15295190802204801

Goldberg, A. E. (2010b). Lesbian and gay parents and their children: Research on the family life cycle. Washington DC: American Psychological Association.

Goldberg, A. E., \& Smith, J. Z. (2011). Stigma, social context, and mental health: lesbian and gay couples across the transition to adoptive parenthood. Journal of Counseling Psychology, 58(1), 139. https://doi.org/10.1037/a0021684

Goldberg, A. E., \& Smith, J. Z. (2014). Predictors of parenting stress in lesbian, gay, and heterosexual adoptive parents during early parenthood. Journal of Family Psychology, 28(2), 125. https:// doi.org/10.1016/j.jsp.2014.08.001

Herek, G. M. (2004). Beyond "homophobia": Thinking about sexual prejudice and stigma in the twenty-first century. Sexuality Research \& Social Policy, 1(2), 6-24. https://doi.org/10.1525/srsp.2004.1.2.6

Hicks, S. (2013). Lesbian, gay, bisexual, and transgender parents and the question of gender. In LGBT-Parent Families (pp. 149-162). Springer, New York, NY.

Howie, C. (2019). Conducting your first systematic review. PsyPAG Quarterly goes electronic, 113, 32-35.

House, J. S. (1981). Work, Stress, and Social Support. MA. Reading: Addison-Wesley.

Huebner, D. M., Mandic, C. G., Mackaronis, J. E., Beougher, S. C., \& Hoff, C. C. (2012). The impact of parenting on gay male couples' relationships, sexuality, and HIV risk. Couple and Family Psychology: Research and Practice, 1(2), 106. https://doi. org/10.1037/a0028497

Kaufman, T. M., Baams, L., \& Dubas, J. S. (2017). Microaggressions and depressive symptoms in sexual minority youth: The roles of rumination and social support. Psychology of Sexual Orientation and Gender Diversity, 4(2), 184. https://doi.org/10.1037/ sgd0000219

Kazyak, E., \& Woodell, B. (2016). Law and LGBQ-parent families. Sexuality \& Culture, 20(3), 749-768. https://doi.org/10.1007/ s12119-016-9335-4

Klittmark, S., Garzón, M., Andersson, E., \& Wells, M. B. (2019). LGBTQ competence wanted: LGBTQ parents' experiences of reproductive health care in Sweden. Scandinavian Journal of Caring Sciences, 33(2), 417-426. https://doi.org/10.1111/scs.12639

Lavner, J. A., Waterman, J., \& Peplau, L. A. (2014). Parent adjustment over time in gay, lesbian, and heterosexual parent families adopting from foster care. American Journal of Orthopsychiatry, 84(1), 46. https://doi.org/10.1037/h0098853

Layland, E. K., Carter, J. A., Perry, N. S., Cienfuegos-Szalay, J., Nelson, K. M., Bonner, C. P., \& Rendina, H. J. (2020). A systematic review of stigma in sexual and gender minority health interventions. Translational Behavioral Medicine, 10(5), 1200-1210. https://doi.org/10.1093/tbm/ibz200 
Leal, D., Gato, J., Coimbra, S. (2019). How does sexual orientation influence family solidarity? An exploratory study. Journal of Prevention and Intervention in the Community, 48(4). https:// doi.org/10.1080/10852352.2019.1627081.

Leal, D., Gato, J., \& Tasker, F. (2019). Prospective parenting: sexual identity and intercultural trajectories. Culture, Health \& Sexuality, 21(7), 757-773. https://doi.org/10.1080/13691058.2018.1515987

Manley, M. H., Goldberg, A. E., \& Ross, L. E. (2018). Invisibility and involvement: LGBTQ community connections among plurisexual women during pregnancy and postpartum. Psychology of Sexual Orientation and Gender Diversity, 5(2), 169. https://doi. org/10.1037/sgd0000285

McGoldrick, M., Preto, N. A. G., \& Carter, B. A. (2015). The expanding family life cycle: Individual, family, and social perspectives. Pearson.

Moher D, Liberati A, Tetzlaff J, Altman DG, The PRISMA Group. (2009). Preferred Reporting Items for Systematic Reviews and Meta-Analyses: The PRISMA statement. PLoS Med, 6(7), e1000097. https://doi.org/10.1371/journal.pmed.1000097

Moher, D., Liberati, A., Tetzlaff, J., \& Altman, D. G. (2010). Preferred reporting items for systematic reviews and meta-analyses: the PRISMA statement. Int J Surg, 8(5), 336-341.

Nelson, S. K., Kushlev, K., \& Lyubomirsky, S. (2014). The pains and pleasures of parenting: When, why, and how is parenthood associated with more or less well-being? Psychological Bulletin, 140(3), 846. https://doi.org/10.1037/a0035444

Paternotte, D. (2018). Coming out of the political science closet: the study of LGBT politics in Europe. European Journal of Politics and Gender, 1(1-2), 55-74. https://doi.org/10.1332/251510818X15272520831175

Perrin, E. C., Pinderhughes, E. E., Mattern, K., Hurley, S. M., \& Newman, R. A. (2016). Experiences of children with gay fathers. Clinical Pediatrics, 55(14), 1305-1317. https://doi.org/10.1177/ 0009922816632346

Pichardo Galán, J. I., Alonso, M., Puche Cabezas, L., \& Muñoz, Ó. (2019). GUIA ADIM LGBTI. Inclusão da diversidade sexual e identidade de género em empresas e organizações. Retrieved from https://eprints. ucm.es/59901/1/200503\%20-\%20Gu\%C3\%ADa\%20ADIM\% 20-\%20PT\%20.pdf

Pilkington, P. D., Milne, L. C., Cairns, K. E., Lewis, J., \& Whelan, T. A. (2015). Modifiable partner factors associated with perinatal depression and anxiety: a systematic review and meta-analysis. Journal of Affective Disorders, 178, 165-180. https://doi. org/10.1016/j.jad.2015.02.023

Riskind, R. G., \& Patterson, C. J. (2010). Parenting intentions and desires among childless lesbian, gay, and heterosexual individuals. Journal of Family Psychology, 24(1), 78. https://doi.org/10.1037/a0017941

Ross, L. E., Steele, L., \& Sapiro, B. (2005). Perceptions of predisposing and protective factors for perinatal depression in same-sex parents. Journal of Midwifery \& Women's Health, 50(6), e65-e70. https:// doi.org/10.1016/j.jmwh.2005.08.002

Ross, L. E., Steele, L., Goldfinger, C., \& Strike, C. (2007). Perinatal depressive symptomatology among lesbian and bisexual women. Archives of Women's Mental Health, 10(2), 53-59. https://doi. org/10.1007/s00737-007-0168-x

Russell, G. M., \& Richards, J. A. (2003). Stressor and resilience factors for lesbians, gay men, and bisexuals confronting antigay politics. American Journal of Community Psychology, 31(3-4), 313-328. https://doi.org/10.1023/A:1023919022811

Santos, A. C. (2004). Nem menos, nem mais, direitos iguais": a juridificação do movimento LGBT português. In Centro de Estudos Sociais da Faculdade de Economia da Universidade de Coimbra, VIII Congresso Luso-Afro-Brasileiro de Ciências Sociais, Coimbra (pp. 16-18).
Santos, C. M., Santos, A. C., Duarte, M., \& Lima, T. M. (2009). Homoparentalidade e desafios ao direito: O caso Silva Mouta na justiça portuguesa e no Tribunal Europeu de Direitos Humanos. Revista Crítica de Ciências Sociais, 87, 43-68. https://doi.org/10.4000/ rccs. 1437

Sarason, B. R., Shearin, E. N., Pierce, G. R., \& Sarason, I. G. (1987). Interrelations of social support measures: Theoretical and practical implications. Journal of Personality and Social Psychology, 52(4), 813. https://doi.org/10.1037/0022-3514.52.4.813

Sherman, A. D., Clark, K. D., Robinson, K., Noorani, T., \& Poteat, T. (2020). Trans* community connection, health, and wellbeing: a systematic review. LGBT Health, 7(1), 1-14. https://doi. org/10.1089/lgbt.2019.0014

Sumontha, J., Farr, R. H., \& Patterson, C. J. (2016). Social support and coparenting among lesbian, gay, and heterosexual adoptive parents. Journal of Family Psychology, 30(8), 987. https://doi. org/10.1037/fam0000253

Tasker, F., and Bellamy, C. (2019). "Adoption by same-sex couples reaffirming evidence: could more children be placed?," in Family Law, ed. R. Lamont (Oxford: Oxford University Press), 171-179.

Tasker, F., \& Delvoye, M. (2015). Moving out of the shadows: Accomplishing bisexual motherhood. Sex Roles, 73(3-4), 125-140. https:// doi.org/10.1007/s11199-015-0503-Z

Tate, D. P., \& Patterson, C. J. (2019). Sexual minority women's attitudes toward infants, children, and parenthood. Journal of Lesbian Studies, 23(4), 464-475. https://doi.org/10.1080/10894160. 2019.1629807

Toomey, R. B., \& Russell, S. T. (2016). The role of sexual orientation in school-based victimization: A meta-analysis. Youth \& Society, 48(2), 176-201. https://doi.org/10.1177/0044118X13483778

Tornello, S. L., \& Patterson, C. J. (2015). Timing of parenthood and experiences of gay fathers: A life course perspective. Journal of GLBT Family Studies, 11(1), 35-56. https://doi. org/10.1080/1550428X.2013.878681

Vasquez del Aguilla, E.; Cantillon, S. (2010). The labour market and LGBT discrimination in Ireland. Social Justice Series, 10(5), 88-105. University College Dublin, School of Social Justice. Retrieved from http://hdl.handle.net/10197/4499

Wall, K., Amâncio, L., \& (orgs.), . (2007). Família e Género em Portugal e na Europa. Imprensa de Ciências Sociais: Lisboa.

Wardecker, B. M., \& Matsick, J. L. (2020). Families of Choice and Community Connectedness: A Brief Guide to the Social Strengths of LGBTQ Older Adults. Journal of Gerontological Nursing, 46(2), 5-8. https://doi.org/10.3928/00989134-20200113-01

Wells, G. (2011). Making room for daddies: Male couples creating families through adoption. Journal of GLBT Family Studies, 7(1-2), 155-181. https://doi.org/10.1080/1550428X.2011.537242

White, R. (1976). Strategies of adaptation an attempt at systematic description. Human coping and adaptation: Coping with life crisis, 47-68. Lexington, MA.

Weston, K. (1991). Families we choose: Lesbians, gays, kinship. New York: Columbia University Press. 